$\begin{array}{llllllllllllllll}W & O & R & K & I & N & G & P & A & P & E & R & 4 & 4\end{array}$ IS THERE AN ASYMMETRIC EFFECT OF M ONETARY POLICY OVER TIME? A $B$ A Y E S I A N A N A L Y S I S

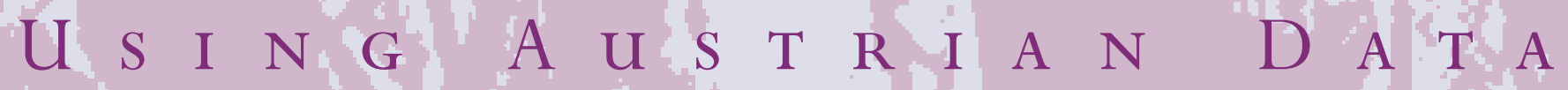




\section{Editorial Board of the Working Papers}

Eduard Hochreiter, Coordinating Editor

Ernest Gnan,

Wolfdietrich Grau,

Peter Mooslechner

Kurt Pribil

\section{Statement of Purpose}

The Working Paper series of the Oesterreichische Nationalbank is designed to disseminate and to provide a platform for discussion of either work of the staff of the OeNB economists or outside contributors on topics which are of special interest to the OeNB. To ensure the high quality of their content, the contributions are subjected to an international refereeing process. The opinions are strictly those of the authors and do in no way commit the OeNB.

Imprint: Responsibility according to Austrian media law: Wolfdietrich Grau, Secretariat of the Board of Executive Directors, Oesterreichische Nationalbank

Published and printed by Oesterreichische Nationalbank, Wien.

The Working Papers are also available on our website:

http://www.oenb.co.at/workpaper/pubwork.htm 


\section{Editorial}

In this paper Sylvia Kaufmann investigates whether monetary policy has asymmetric effects over the business cycle. For this she estimates a univariate model for GDP that additionally includes the first difference of the 3-month Austrian interest rate as a measure for monetary policy. The asymmetry of the effects is captured by allowing for state-dependent parameters where the latent state variable follows a Markov switching process. The model itself is estimated within a Bayesian framework using Markov Chain Monte Carlo simulation methods. The results document significant negative effects of monetary policy during periods of below-average growth, while the effects seem insignificant during periods of normal or above-average growth, thereby lending support to theoretical models with price rigidities that imply a convex supply curve.

May 18, 2001. 



\title{
Is there an asymmetric effect of monetary policy over time? A Bayesian analysis using Austrian data.
}

\author{
Sylvia Kaufmann ${ }^{1}$
}

May, 2001

\begin{abstract}
The present paper assesses whether monetary policy effects are asymmetric over the business cycle by estimating a univariate model for GDP including additionally the first difference of the 3-month Austrian interest rate as a measure for monetary policy. The asymmetry of the effects is captured by allowing for state-dependent parameters where the latent state variable follows a Markov switching process. The model is estimated within a Bayesian framework using Markov Chain Monte Carlo simulation methods. Model selection and specification tests are performed by means of marginal likelihood. The results document significant negative effects of monetary policy during periods of below-average growth, while the effect seems insignificant during periods of normal- or above-average growth. These results corroborate those derived in theoretical models assuming price rigidities and implying a convex supply curve. Additionally, the concern of using appropriate state-identifying restrictions is raised to obtain an unbiased posterior inference. Finally, the analysis concludes by assessing the robustness of the results w.r.t. alternative measures of monetary policy.
\end{abstract}

Keywords: Asymmetry, monetary policy, Markov switching, Markov Chain Monte Carlo, marginal likelihood.

\footnotetext{
${ }^{1}$ Oesterreichische Nationalbank, Economic Analysis Division and University of Vienna, Department of Economics. Correspondence: Oesterreichische Nationalbank, Otto Wagner Platz 3, 1090 Vienna, sylvia.kaufmann@oenb.co.at I thank an anonymous referee for critical comments. The usual disclaimer applies. Finally, the views expressed in the paper are strictly those of the author and do in no way commit the OeNB.
} 



\section{Introduction}

In the literature there are given basically two theoretical explanations for asymmetric effects of monetary policy. The models presented predict that monetary policy is more effective during recessions than during expansions. One strand builds on downward price rigidity. Ball and Mankiw (1994) present a model in which firms change their prices regularly and, if paying a menu cost, can make special adjustments in response to shocks. Asymmetries arise if a positive trend inflation is added to the model. The approach implies a convex short-run aggregate supply curve. During expansion - i.e. at the relatively steep part of the supply curve - monetary policy actions, measured by their influence on the aggregate demand curve, result mainly in price changes rather than output changes whereas in recessionary periods - at the flat part of the supply curve - monetary policy actions mainly affect output. Tsiddon (1993) derives that given fixed costs of changing a nominal price an increase in the average rate of monetary expansion leads to a decrease in the lag of price adjustment in response to a positive shock.

The second approach is based on the external finance premium - the difference between external (by issuing debt or equity) and internal (e.g. retained earnings) finance. During tight-monetary periods informational frictions in the credit markets worsen and enhance the effects of monetary policy on the real economy (see Bernanke and Gertler (1995) for an overview). Two potential channels are identified to magnify monetary policy actions. The deteriorating effect of a monetary contraction on borrowers' net worth (balance sheet) increases interest rates even further through an increase in the external finance premium. In Bernanke and Gertler (1989) asymmetric information gives rise to agency costs of financing real capital investments which is reflected in the external finance premium. Farmer $(1985,1988)$ builds a model of financial contracting in the presence of asymmetric information and limited collateral: increases in interest rates lead firms to write contracts in which layoffs occur more frequently. Recently, Kiyotaki (1998) and Kiyotaki and Moore (1997b, 1997a) present a model in which credit constraints arise because creditors cannot force debtors to repay debts unless they are secured by collateral. The credit system becomes a propagation mechanism by which the effects of shocks persist and amplify through the interactions between collateral, borrowers' net worth and credit limits. Relatively small shocks to technology or to wealth distribution can then generate large persistent fluctuations in output and employment. Finally, credit market imperfections give raise to an endogenous regime-switching mechanism between different equilibrium states in the business cycle model of Azariadis and Smith (1998).

Aggregate empirical evidence in favor of asymmetric effects of monetary policy is presented in several papers, including Cover (1992), Karras (1996a, 1996b) and Lenz (1997) among others. Cover's approach is based on a two-step procedure. The first step estimates a money-supply process to identify the endogenous component of monetary policy. The residuals of this equation are interpreted as the innovation in monetary policy, i.e. the monetary policy shock. These are included in the second equation estimating the output process of the system where the specification allows for different effects of negative and positive values of monetary policy shocks. A test on equal effects of positive and negative 
values is rejected. The evidence thus supports the view that negative money supply shocks have a larger and more important effect on output than positive shocks. The same system of equations is estimated in Karras (1996a, 1996b) and Lenz (1997) simultaneously using nonlinear least squares methods. The evidence supports again differential effects of positive and negative monetary policy shocks.

Garcia and Schaller (1995) and Kakes (1998) take another approach and investigate the asymmetric effect of monetary policy applying the Markov switching model presented in Hamilton $(1990,1989)$. Based on a univariate model for the growth rates of output and industrial production, respectively, they find evidence for a statistically significant asymmetric effect of interest rate changes over the business cycle. Peersman and Smets (2001) investigate industrial production of the countries participating in the Eurosystem. They document an overall negative effect of unexpected monetary policy innovations for most of the countries, asymmetric effects in individual countries are reported for France, Germany, and Spain only, however.

The present paper presents evidence on Austria in this line of research. The model is estimated within a Bayesian framework using Markov Chain Monte Carlo (MCMC) simulation methods (see Smith and Roberts (1993) and Chib and Greenberg(1996) for an overview on MCMC methods). There is few literature on MCMC applications to Markov switching models to macroeconomic data in particular. Kim and Nelson (1998) estimate a dynamic factor model with Markov switching to get a coincident index of the business cycle and to assess duration dependence. Within the same setting, Kaufmann (2000) infers business cycle turning points, performs additionally model selection by means of marginal likelihoods and applies diagnostic measures to assess the model fit. An overview of additional applications to economic data is also found in Kim and Nelson (1999). The present paper uses the permutation sampler derived in Frühwirth-Schnatter (2001) to estimate the model. Model selection and specification tests are performed by means of marginal likelihoods using results of Frühwirth-Schnatter (1999) who presents a detailed analysis on marginal likelihoods for mixture and Markov switching models.

The analysis uses quarterly data on Austrian GDP and the first difference of the 3month interest rate as a measure for monetary policy covering the period from 1976 to 1998. As the Austrian Schilling was pegged to the German Mark from 1981 onwards, monetary policy stance coming from Germany is most likely to be reflected in Austrian interest rates. $^{2}$ We can infer two regimes that refer to periods of below- and above-average growth, respectively. The effect of interest rate increases seem to be significantly negative in periods of below-average growth. The inference on the posterior state probabilities can be related to specific business cycle periods. One classification however, seems to be an artifact of the effect that the anticipated introduction of the luxury tax had on sales in the last quarter of 1977 and the first quarter of 1978. Restricting the sample to exclude this outlier does not change the basic evidence in favor of the switching specification. Rather, the results are refined and the relation of the latent state variable to business

\footnotetext{
${ }^{2}$ Indeed, the correlation between the Austrian and German interest rate is above 0.97 for the sample 1981 through 1998, and the one between the first differences is near 0.7 and above 0.9 for the observation period beginning in 1981 and 1990, respectively.
} 
cycle periods becomes more obvious. Additional results document the usefulness of the random permutation sampler to find adequate state identifying restrictions. It turns out that poor constraints, i.e. constraints that do not uniquely identify the states, may biase the results considerably. Moreover, the results are robust w.r.t. the measure of monetary policy stance. The inference changes only marginally when using the interest rate level rather than its first difference. A final investigation using the residuals of a structural vector autoregression (SVAR) as a measure for domestic monetary policy shocks obtains only marginal negative effects on real activity, that are not asymmetric over time, however. A fact that reflects the close integration of the Austrian with the German economy.

The next section specifies the model and presents the assumption about the prior distributions completing the Bayesian specification. Section 3 summarizes the sampling scheme. An estimator of the model likelihood is given in section 4 . The results are discussed in section 5, and the robustness analysis follows in section 6 . Finally, section 7 concludes by comparing the results to those reported in a selection of papers analyzing European countries, and closely related to the present one.

\section{Model specification, prior specification}

Let $y^{N}=\left(y_{1}, \ldots, y_{N}\right)$ represent a $N \times 1$ vector of observable variables. The general form of the model investigated here takes the following form:

$$
y_{t}=X_{t} \beta_{S_{t}}+\varepsilon_{t}, \quad \varepsilon_{t} \sim \text { i.i.d. } \mathcal{N}\left(0, \sigma_{S_{t}}\right),
$$

where $X_{t}$ may also contain lagged dependent variables. The time-varying parameters $\beta_{S_{t}}$ and $\sigma_{S_{t}}$ take on one out of $K$ values depending on the regime prevailing in period $t, \beta_{S_{t}}=\beta_{j}$ and $\sigma_{S_{t}}=\sigma_{j}$ iff $S_{t}=j, j=1, \ldots, K$. The process governing the latent state variable $S_{t}$ is assumed to be Markovian of order one with transition probabilities $\eta_{i j}=P\left(S_{t}=j \mid S_{t-1}=i\right)$, where $\sum_{j=1}^{K} \eta_{i j}=1$.

Within the present paper we will analyze whether a real macroeconomic variable, specifically the growth rate of GDP, is affected by monetary policy actions, and whether these effects are asymmetric over time. The intuition behind the latent specification of the state process is the fact, that the prevailing economic regime is usually not directly observed, and the Markovian property captures the fact that economic regimes are thought to persist for some time. The persistence of regimes might differ, however, which is reflected by the transition probabilities.

Note that as it stands the model is not identified for state specific parameters w.r.t. state permutations. For a given permutation $\rho=\left(\rho_{(1)}, \ldots, \rho_{(K)}\right)$ the model likelihood is not changed for an appropriate reordering of the state specific parameters, $\tilde{\beta}=\rho(\beta)$ and $\tilde{\sigma}=\rho(\sigma)$, and the respective permutation of the state variable $\tilde{S}_{t}=\rho\left(S_{t}\right), t=1, \ldots, N$. Usually, economic intuition or the purpose of the analysis itself yield restrictions that identify state specific parameters. In our case, thinking of asymmetry over time a natural 
restriction would be to associate the first state with periods of economic slowdown and a second state with periods of economic recovery, i.e. ordering the state specific parameters according to one or more elements in $\beta$ :

$$
\beta_{1, i}<\cdots<\beta_{K, i}
$$

where $i$ is either value out of $1, \ldots, K$. Obviously, there is a problem of choosing the parameters w.r.t. which the system is identified. Potentially, the states might even be very poorly separable in terms of $\beta$, but well separable in terms of the persistence parameters $\eta_{i i}$. In such cases, a restriction on $\eta$, like $\eta_{11}<\cdots<\eta_{K K}$, would identify the state specific parameters. Sometimes a combination of the two might be appropriate (see e.g. Kaufmann and Frühwirth-Schnatter (2000) for an example). The next section presents the sampler on which we base the inference. It also highlights the use of the random permutation sampler (Frühwirth-Schnatter, (2001)) in a first round to find adequate identifying restrictions.

Before turning to this, we conclude the model specification by a discussion of its hierarchical structure. For ease of exposition, we introduce the following notation. $S^{N}=$ $\left(S_{1}, \ldots, S_{N}\right)$ gathers all state variables up to time $N$, and a corresponding realization is denoted by $s^{N}=\left(s_{1}, \ldots, s_{N}\right) . \eta=\left(\eta_{1}, \ldots, \eta_{K}.\right)$, with $\eta_{i} .=\left(\eta_{i 1}, \ldots, \eta_{i K}\right)$, collects the transition probabilities. $\phi=(\beta, \sigma, \eta)$ collects all model parameters, where $\beta=\left(\beta_{1}, \ldots, \beta_{K}\right)$ and $\sigma=\left(\sigma_{1}, \ldots, \sigma_{K}\right)$. The "augmented parameter vector" $\theta=\left(\phi, S^{N}\right)$ includes additionally the vector of the latent state variables. Conditional on a known realization for $S^{N}$, the data likelihood factorizes as

$$
L\left(y^{N} \mid \phi, s^{N}\right)=\prod_{t=1}^{N} f\left(y_{t} \mid y^{t-1}, \phi, s_{t}\right),
$$

where the one-step ahead predictive distribution is Gaussian

$$
f\left(y_{t} \mid y^{t-1}, \phi, s_{t}\right)=\sqrt{\frac{1}{2 \pi \sigma_{s_{t}}}} \exp \left\{\frac{\left(y_{t}-X_{t} \beta_{s_{t}}\right)^{2}}{2 \sigma_{s_{t}}}\right\} .
$$

The density of the prior distribution for $s^{N}, \pi\left(s^{N} \mid \eta\right)$, depends only on the transition distribution $\eta$, and is proportional to

$$
\begin{gathered}
\pi\left(s^{N} \mid \eta\right) \propto \prod_{t=1}^{N} \eta_{s_{t}, s_{t-1}} \pi\left(s_{0}\right)=\prod_{j=1}^{K} \prod_{i=1}^{K} \eta_{i j}^{N_{i j}} \pi\left(s_{0}\right), \\
N_{i j}=\#\left\{s_{t}=j \mid s_{t-1}=i\right\} .
\end{gathered}
$$

To bring amenable the model to Bayesian estimation we need to specify a prior distribution for the model parameter $\phi, \pi(\phi)$. We have to use proper prior distributions as improper priors on state specific parameters will lead to improper posterior distributions in the case where no observation will be assigned to a specific state. The following assumptions determine the specification about the prior distribution: 
- The parameters $\beta, \sigma$ and $\eta$ are independent a priori, $\pi(\phi)=\pi(\beta) \pi(\sigma) \pi(\eta)$.

- $\beta$ is assumed normal $\mathcal{N}\left(b_{0}, B_{0}^{-1}\right)$.

- $\sigma_{1}, \ldots, \sigma_{K}$ are independent a priori. A natural prior is an inverse Gamma, $\sigma_{i} \sim$ $I G\left(g_{0}, G_{0}\right), i=1, \ldots, K$.

- $\eta_{1}, \ldots, \eta_{K}$. are independent a priori, and are assumed to have a Dirichlet prior distribution, $\eta_{i} . \sim D\left(e_{1}, \ldots, e_{K}\right)$.

The specification of the prior distribution on the model parameters assumes state independent hyperparameters. Thus, the prior is invariant w.r.t. state permutations. Moreover, the prior integrates to one which makes it readily available for the estimation of the marginal likelihood using the bridge sampling techniques discussed in detail for mixture and switching models in Frühwirth-Schnatter (1999).

\section{The sampling scheme}

The estimation of the model parameters and of the latent state variables is based on Markov chain Monte Carlo (MCMC) simulation methods using the permutation sampler proposed in Frühwirth-Schnatter (2001). Due to the hierarchical structure of the model we get the inference on the joint posterior distribution of the augmented parameter vector by iteratively sampling out of the following conditional posterior distributions:

(i) $\pi\left(S^{N} \mid \phi, y^{N}\right)$

(ii) $\pi\left(\eta \mid s^{N}\right)$

(iii) $\pi\left(\beta \mid \sigma, s^{N}, y^{N}\right)$

(iv) $\pi\left(\sigma \mid \beta, s^{N}, y^{N}\right)$

Step (i) and (ii) are by now standard in the literature. Albert and Chib (1993) derived a single-move sampler for the latent state variable vector $S^{N}$. Here instead, we will sample $S^{N}$ in a multi-move manner as described in detail in Chib (1996), Carter and Kohn (1994) and Shepard (1994). Given $S^{N}$, the posterior distribution of $\eta$ is a product of $K$ independent Dirichlet distribution,

$$
\pi\left(\eta \mid s^{N}\right)=\prod_{i=1}^{K} \pi\left(\eta_{i} \cdot s^{N}\right)=\prod_{i=1}^{K} D\left(e_{i 1}+N_{i 1}, \ldots, e_{i K}+N_{i K}\right) .
$$

Step (iii) is based on a regression with heteroskedastic errors. We rewrite equation (1) as

$$
y_{t}=S_{t}^{1} \cdot X_{t} \beta_{1}+\cdots+S_{t}^{K} \cdot X_{t} \beta_{K}+\varepsilon_{t}, \varepsilon_{t} \sim \mathcal{N}\left(0, \sigma_{s_{t}}\right)
$$

where $S_{t}^{j}=1$ iff $S_{t}=j$ and 0 otherwise, $j=1, \ldots, K$. Combining the prior distribution with (8), the posterior distribution of $\beta$ is multivariate normal,

$$
\pi\left(\beta \mid \sigma, s^{N}, y^{N}\right)=\mathcal{N}(b, B),
$$


where $b=B\left(Z^{\prime} W y+B_{0} b_{0}\right)$ and $B=\left(Z^{\prime} W Z+B_{0}\right)^{-1} . \quad y=y^{N}$ gathers all left-hand variables in (8) and $Z$ is the predictor matrix of the system,

$$
Z=\left[\begin{array}{ccc}
S_{1}^{1} \cdot X_{1} & \cdots & S_{1}^{K} \cdot X_{1} \\
\vdots & & \vdots \\
S_{N}^{1} \cdot X_{N} & \cdots & S_{N}^{K} \cdot X_{N}
\end{array}\right]
$$

The weighting matrix $W$ takes into account the heteroskedastic nature of the observations, $W=\operatorname{diag}\left(w_{1}, \ldots, w_{N}\right)$, where $w_{t}=\sigma_{s_{t}}^{-1}$.

Step (iv) samples the vector $\sigma=\left(\sigma_{1}, \ldots, \sigma_{K}\right)$. Given all other model parameters and $s^{N}$, the posterior distribution of $\sigma$ is a product of independent inverse Gamma distributions:

$$
\pi\left(\sigma \mid \beta, s^{N}, y^{N}\right)=\prod_{i=1}^{K} \pi\left(\sigma_{i} \mid \beta, s^{N}, y^{N}\right)=\prod_{i=1}^{K} I G\left(g_{i}, G_{i}\right),
$$

where $g_{i}=g_{0}+0.5 \cdot \sum_{t=1}^{N} S_{t}^{i}$ and $G_{i}=G_{0}+0.5 \cdot \sum_{t=1}^{N} S_{t}^{i}\left(y_{t}-Z_{t} \beta\right)^{2}$, with $Z_{t}$ denoting the $t$ th row of the matrix $Z$.

Throughout we sample out of the unconstrained posterior, i.e. the acceptance of the sampled values is not conditioned on a state identifying restriction. Therefore, a permutation step completes the sampling scheme. To reach an identified model, a permutation $\rho$ is defined that ensures the identifiability constraint as e.g. in (2)

$$
\begin{aligned}
\left(\beta_{1}, \ldots, \beta_{K}\right) & :=\left(\beta_{\rho(1)}, \ldots, \beta_{\rho(K)}\right) \\
\left(\sigma_{1}, \ldots, \sigma_{K}\right) & :=\left(\sigma_{\rho(1)}, \ldots, \sigma_{\rho(K)}\right) \\
s^{N} & :=\left(\rho\left(s_{0}\right), \rho\left(s_{1}\right), \ldots, \rho\left(s_{N}\right)\right) \\
\eta & :=\left(\tilde{\eta}_{1}, \ldots, \tilde{\eta}_{K}\right), \quad \tilde{\eta}_{i .}:=\left(\eta_{\rho(i), \rho(1)}, \ldots, \eta_{\rho(i), \rho(K)}\right) .
\end{aligned}
$$

If a suitable identifying restriction is not available or is not known a priori, then postprocessing the MCMC output of a random permutation sampler in an exploratory way often proves to be a useful tool in finding such a restriction. To this aim, the permutation step consists in a random permutation of the sampled values in order to explore the unrestricted posterior distribution of the model parameters.

\section{Model selection}

Normally, the number of autoregressive lags $p$, of distributed lags of the exogenous variable, $q$, as well as the number of states, $K$, are not known a priori. Within the Bayesian context of the paper we will perform order selection by means of the marginal likelihood $L\left(y^{N} \mid K, p, q\right)$. With the use of the state-independent prior integrating to one described above, marginal likelihoods may be estimated then either by using the MCMC output exploring the unconstrained posterior distribution or the one exploring the posterior constrained to the identifying restriction. Using the derivation in Frühwirth-Schnatter (1999) 
we have (the conditioning on $p, q$ and $K$ is suppressed on the left-hand side for expositional convenience):

$$
L\left(y^{N} \mid p, q, K\right)=\int L\left(y^{N} \mid \phi\right) \pi(\phi) d \phi=K ! \int_{\mathcal{R}} L\left(y^{N} \mid \phi\right) \pi(\phi) d \phi,
$$

where $\mathcal{R}$ represents the parameter space restricted to fulfill the state identifying restriction. Note that the dimensionality of integration is substantially reduced by the fact that analytical integration w.r.t. $s^{N}$ is possible. An explicit formula for the marginal likelihood $L\left(y^{N} \mid \phi\right)$ in (12) is given by integrating w.r.t. to $s_{t}$ the observation density in (4), $L\left(y^{N} \mid \phi\right)=\prod_{t=1}^{N} \sum_{s_{t}=1}^{K} f\left(y_{t} \mid y^{t-1}, \phi, s_{t}\right) \pi\left(s_{t} \mid y^{t-1}, \phi\right)$. Several methods have been presented in the literature to estimate marginal likelihoods from the MCMC output. A detailed analysis on estimating the marginal likelihood of mixture and switching models is presented in Frühwirth-Schnatter (1999). She applies and compares the performance of the candidate's formula (Chib (1995)), importance sampling based on mixture approximations (Frühwirth-Schnatter (1995)) and bridge sampling (Meng and Wong, (1996)). It turns out that the bridge sampler has several advantages over the other methods. Whereas the candidate's formula needs a well-identified model to yield an unbiased estimate of the marginal likelihood, the bridge sampler yields an unbiased estimate of it without the need to identify state-specific parameters. Moreover, the most precise estimate of the marginal likelihood is obtained when combining the MCMC output of the random permutation sampler with a sample out of an importance density $q(\phi)$. To approximate the posterior distribution of the parameters in a simple way, we will assume $q(\phi)$ to be a mixture of the densities given in (7), (9) and (10):

$$
q(\phi)=1 / L \sum_{l=1}^{L} \pi\left(\eta \mid s^{N^{(l)}}\right) \pi\left(\beta \mid y^{N}, s^{N^{(l)}},(\eta, \sigma)^{(l)}\right) \pi\left(\sigma \mid y^{N}, s^{N^{(l)}},(\eta, \beta)^{(l)}\right),
$$

where the elements $(l)$ entering the mixture in (13) are chosen randomly from the simulations of the MCMC output.

\section{$5 \quad$ Results}

The model described so far is applied to quarterly real GDP growth and the first difference of the Austrian 3-month interest rate to assess whether the effects of monetary policy are asymmetric over time. GDP is seasonally adjusted, the data cover the period from the first quarter of 1976 to the last quarter of 1998. Figure 3, bottom panel, depicts the series used in the analysis. The most general version of the model investigated allows for state dependent parameters except the autoregressive ones. Thus the explicit specification of equation (1) writes:

$$
y_{t}=\mu_{S_{t}}+\sum_{i=1}^{p} \beta_{y i} y_{t-i}+\sum_{i=1}^{q} \beta_{m S_{t}, i} x_{t-i}+\varepsilon_{t}, \quad \varepsilon_{t} \sim \text { i.i.d. } \mathcal{N}\left(0, \sigma_{S_{t}}\right),
$$


where $y_{t}$ stands for the growth rate of GDP and $x_{t}$ represents the measure for monetary policy, in particular the first difference of the interest rate. Including only lags of the interest rate reflects the usual identifying assumption that GDP reacts with a lag to monetary policy actions.

For the estimation, the hyperparameters of the prior distribution were set according to:

- $\beta \sim \mathcal{N}(0, I)$, where $I$ is the identity matrix, and $\beta=\left(\mu_{1}, \ldots, \mu_{K}, \beta_{y, 1}, \ldots, \beta_{y p}, \beta_{m 1,1}, \ldots, \beta_{m K, q}\right)$.

- $\sigma_{i} \sim I G(1,2), i=1, \ldots, K$,

- $\eta_{i} . \sim D(1, \ldots, 1)$.

These priors reflect rather vague information on the model parameters. Note that we do not restrict the prior to the stationary space for the autoregressive process. It turns out that the sampler by itself yields autoregressive coefficients characterizing a stationary process with coefficient estimates well below one for all model specifications investigated. An alternative would be to use a truncated prior that restricts the parameter space to ensure a stationary autoregressive process. However, in this case, the prior would not integrate to one which would have to be accounted for when estimating the marginal likelihood.

Table 1: Marginal likelihoods (standard errors in parenthesis) estimated by the bridge sampler for given lag orders $p$ and $q$ of the 2-states model. The estimation is based on the random permutation sampler. Throughout, 1'000 out of the 6'000 sampled values of the posterior distribution are randomly selected to construct the mixture density $q(\phi)$.

\begin{tabular}{|lrrrrrrr|}
\hline \hline & $q$ & 5 & 4 & 3 & 2 & 1 \\
$p$ & & & & & & \\
\hline 4 & -128.519 & -129.601 & -130.284 & -128.724 & -126.429 & -123.931 \\
& $(0.012)$ & $(0.011)$ & $(0.012)$ & $(0.013)$ & $(0.009)$ & $(0.012)$ \\
3 & -126.318 & -127.369 & -128.007 & -127.629 & -125.402 & -122.882 \\
& $(0.011)$ & $(0.011)$ & $(0.011)$ & $(0.011)$ & $(0.008)$ & $(0.008)$ \\
2 & -124.698 & -125.697 & -126.308 & -125.899 & -124.934 & $\mathbf{- 1 2 2 . 4 0 1}$ \\
& $(0.009)$ & $(0.011)$ & $(0.011)$ & $(0.011)$ & $(0.009)$ & $(0.008)$ \\
1 & -122.955 & -123.869 & -124.731 & -124.156 & -122.885 & -123.621 \\
& $(0.010)$ & $(0.009)$ & $(0.010)$ & $(0.009)$ & $(0.009)$ & $(0.006)$ \\
\hline$\sigma_{1}=\sigma_{2}, p=2, q=1:-\mathbf{- 1 2 0 . 7 2 3}(0.007)$ & & & \\
\hline \hline
\end{tabular}

In a first round, we compute the marginal likelihood of various model specification of order $p$ and $q$, the highest order being 4 and 6 , respectively. It proved to be very hard however, to find an identifying restriction that uniquely discriminated between the states across all model specifications. Therefore, we use the random permutation sampler to explore the unconstrained posterior distribution of the parameters, and the best parsimonious 
model specification is chosen according to the marginal likelihood estimated by means of bridge sampling. Table 1 summarizes the marginal likelihoods for the various lag order specification. The estimates are based on 6'000 iterations of the sampler after an initial burn-in phase of 2'000 iterations to get rid of the dependence on initial conditions. 1'000 sampled values are selected randomly to form the importance density in (13). The appropriate parsimonious representation in terms of marginal likelihood sets $p=2$ and $q=1$. The bottom panel of the table documents that the marginal likelihood is even better for the specification that assumes a state-independent variance. Thus, in the following we will discuss the results of a 2 -state, state-independent variance model specification with $p=2$ and $q=1$.

Figure 1: Markov switching model with the interest rate difference for $p=2, q=1$, and no switching variances. Scatter plots of sampled values for $\mu_{i}$ and $\beta_{m i, j}$ against persistence $\eta_{i i}, i, j=1,2$, and against each other, panel (a), (b) and (c) respectively.

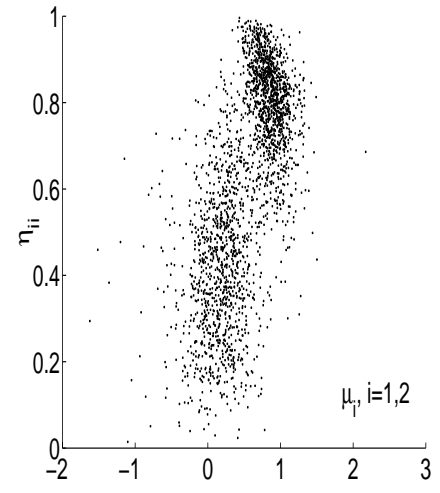

(a)

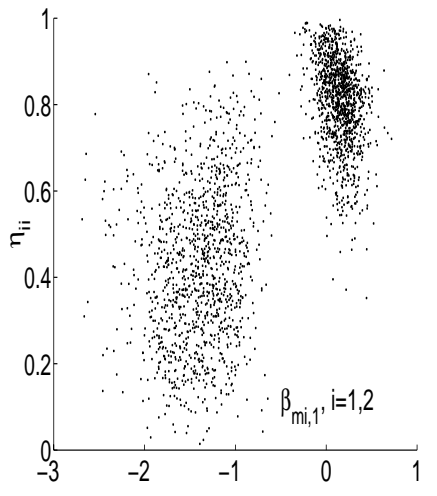

(b)

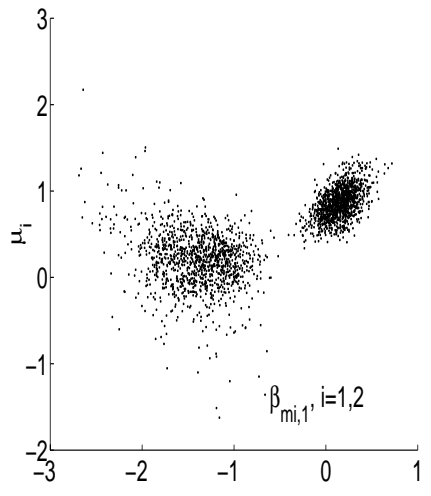

(c)

Figure 2: Markov switching model with interest rate difference for $p=2$ and $q=1$. Identified model with $\beta_{m 1,1}<\beta_{m 2,1}$. Posterior distribution for $\eta_{i i}, \mu_{i}$ and $\beta_{m i, 1}, i=1,2$, panel (a), (b) and (c), respectively.

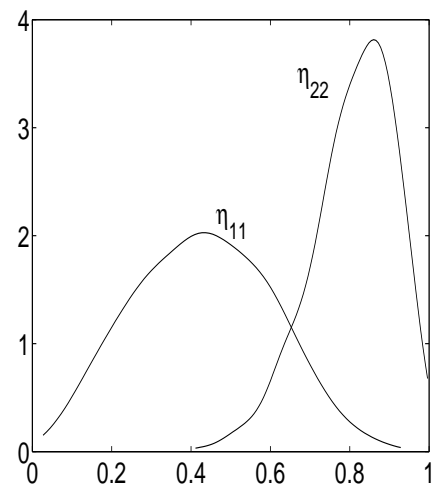

(a)

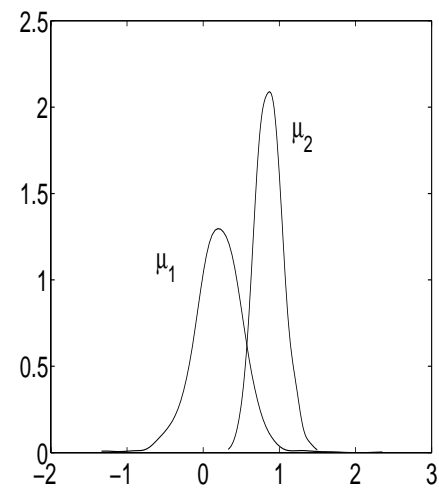

(b)

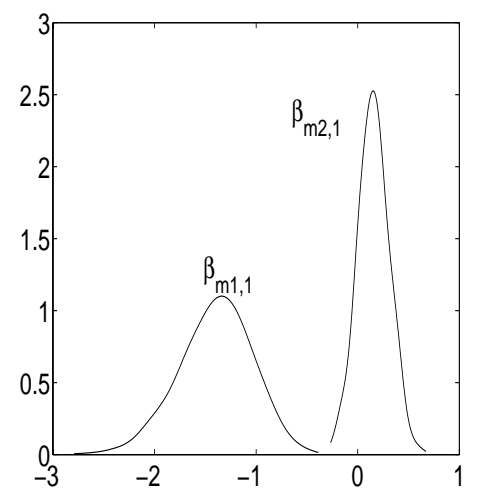

(c)

To find an adequate state-identifying restriction, the MCMC output of the random permutation sampler is post-processed in an exploratory manner. Figure 1 provides scatter plots of the sampled values for $\mu$ and $\beta$ against persistence and against each other, respectively. Whereas it seems difficult to discriminate the states by means of the persistence 
parameters $\eta_{i i}$ or the constant $\mu_{i}, i=1,2$, panel (b) and (c) clearly reveal that the states might be identified by means of $\beta_{m i, 1}$. The constrained permutation sampler was then used to infer the state-dependent parameters and the posterior state probabilities by assuming $\beta_{m 1,1}<\beta_{m 2,1}$.

Table 2: Markov switching model with interest rate difference for $p=2$ and $q=1$. Posterior distribution of the model parameters.

\begin{tabular}{|l|rrrrr|}
\hline \hline par & \multicolumn{1}{|c}{ mean } & sd & median & \multicolumn{2}{c|}{$95 \%$ conf.int. } \\
\hline$\mu_{1}$ & 0.2041 & 0.3135 & 0.2153 & -0.4414 & 0.7767 \\
$\mu_{2}$ & 0.8650 & 0.1851 & 0.8593 & 0.5268 & 1.2332 \\
$\beta_{y 1}$ & -0.0861 & 0.1050 & -0.0858 & -0.2964 & 0.1238 \\
$\beta_{y 2}$ & -0.0814 & 0.1085 & -0.0802 & -0.3011 & 0.1228 \\
$\beta_{m 1,1}$ & -1.4040 & 0.3604 & -1.3794 & -2.1715 & -0.7700 \\
$\beta_{m 2,1}$ & 0.1509 & 0.1537 & 0.1474 & -0.1438 & 0.4591 \\
$\sigma$ & 0.5231 & 0.1041 & 0.5094 & 0.3559 & 0.7627 \\
$\eta_{11}$ & 0.4370 & 0.1749 & 0.4351 & 0.1141 & 0.7767 \\
$\eta_{12}$ & 0.5630 & 0.1749 & 0.5649 & 0.2228 & 0.8856 \\
$\eta_{21}$ & 0.1934 & 0.1045 & 0.1810 & 0.0319 & 0.4326 \\
$\eta_{22}$ & 0.8066 & 0.1045 & 0.8190 & 0.5673 & 0.9681 \\
\hline marginal likelihood: $-120.723(0.007)$ \\
marginal likelihood with $\beta_{m 1, i}=\beta_{m 2, i}:-127.898(0.007)$ \\
marginal likelihood with $K=1:-128.081$ \\
\hline \hline
\end{tabular}

Table 2 summarizes the posterior distribution of all model parameters, and figure 2 displays the marginal posterior distributions of the state dependent parameters. The posterior distributions overlap in some cases, the states seem to be well-discriminated using the restriction on $\beta_{m i, 1}$, however. Mean, standard error and median of the posterior distribution (see table 2) are simply computed by taking the mean, the standard deviation and the median of the retained MCMC output values, respectively. The $95 \%$ confidence interval is estimated using the lower and the upper 2.5th percentiles. One state seems to pertain to a below average growth state with low persistence, the mean persistence to remain in the prevailing state being lower than the mean probability to switch. The second state relates to above average-growth periods and displays a considerable persistence. Our hypothesis of a stronger effect of monetary policy during periods of subdued economic performance is not rejected by the results, $\beta_{m 1,1}$ being much lower than $\beta_{m 2,1}$, and significantly negative. The bottom panel of table 2 reports the marginal likelihood of the estimated model along with marginal likelihoods of additional restricted specifications. In any case, the model with state dependent parameters outperforms a specification assuming state-independent effects of monetary policy $\left(\beta_{m 1, i}=\beta_{m 2, i}\right)$ and one assuming overall state-independent parameters $(\mathrm{K}=1)$.

Finally, the posterior smoothed state probabilities $P\left(S_{t} \mid y^{N}\right)$ are depicted in figure 3 along with the series for GDP growth and the interest rate difference. These are computed by 
averaging over the 6'000 values of the MCMC output. At first sight, it is not obvious that the states relate to specific business cycle periods. However, the prevalence of state one clusters around periods of economic slowdown. This relates in particular to the dates around $1980 / 81,1983 / 84$ and 1986/87. The classification of the first quarter of 1978 is an artifact due to the effect that the anticipated introduction of a luxury tax (a tax on mostly imported goods) had on sales. Finally, as the economic slack of the years 1992/1993, quite strong in major EU countries, fell out only moderately in Austria, the sampler fails to clearly classify it to one of the two states.

Figure 3: Markov switching model with interest rate difference for $p=2$ and $q=1$. Posterior state probabilities with a plot on GDP growth and the interest rate difference.
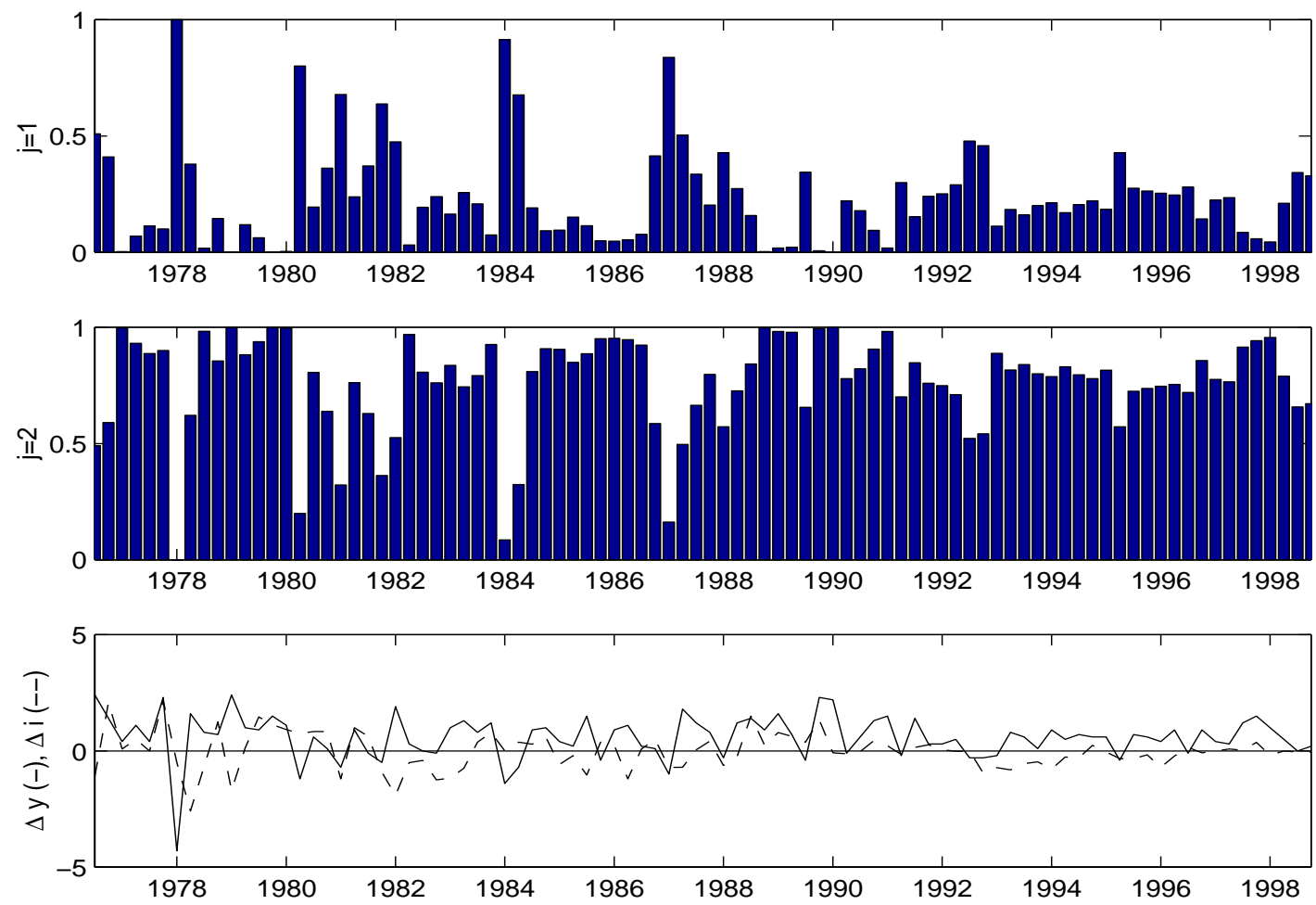


\section{$6 \quad$ Robustness analysis}

\subsection{Using a different restriction}

Figure 4: Markov switching model with interest rate difference for $p=2$ and $q=1$. Identified model with $\mu_{1}>\mu_{2}$. Posterior distribution for $\eta_{i i}, \mu_{i}$ and $\beta_{m i, 1}, i=1,2$, panel (a), (b) and (c), respectively.

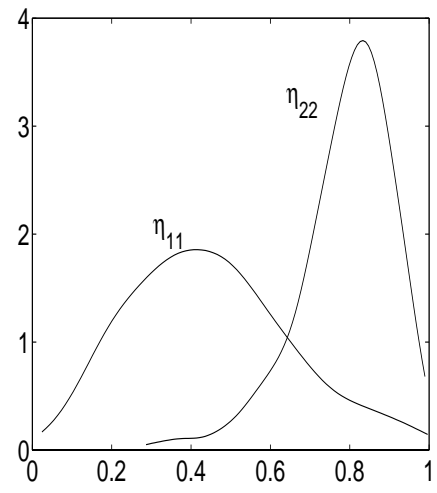

(a)

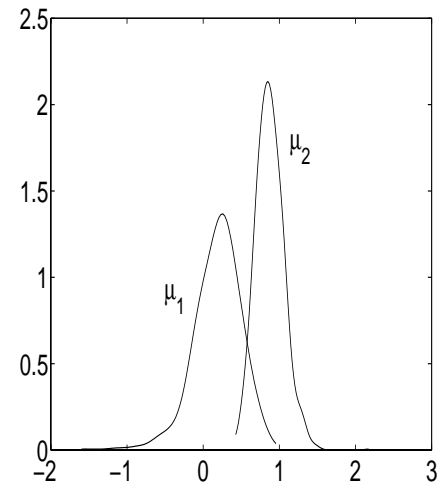

(b)

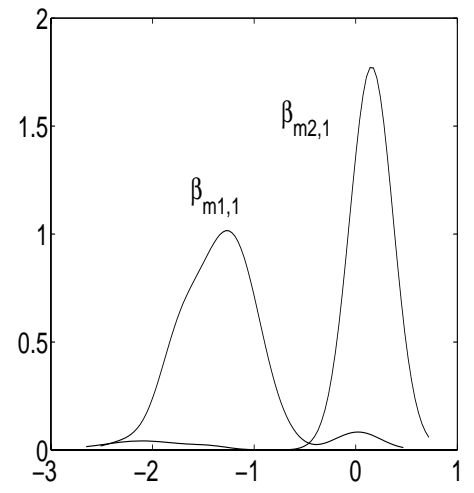

(b)

In the previous section we emphasized the use of the random permutation sampler to find an appropriate, unique state-identifying restriction. Many macroeconomic applications however, estimate a constrained model, and a usual restriction for the present model would be $\mu_{1}<\mu_{2}$. Figure 4 depicts the posterior distribution of the state dependent parameters obtained using this identifying constraint. Three major concerns arise. First, the posterior distributions of the persistence and of $\beta$ are multimodal, which would lead to a biased posterior inference on these parameters presented in table 2 . Second, the inference on $\mu$ would yield wider confidence intervals, hence less precision. Third, estimates of the marginal likelihood would also be biased as the importance density builds on a normal approximation of the posterior distribution, this would interfere with model selection and might potentially biase the results towards a no switching specification.

\subsection{Estimating the model without the outlier}

To assess the influence of the outlier in GDP growth in the first quarter of 1978, we estimate the model for the restricted sample period beginning in 1978/2. The best specification in terms of marginal likelihood sets $p=1$ and $q=1$. The results are displayed in table 3. Basically, the Markov switching specification still outperforms the specification assuming state-independent parameters on the interest rate difference and a noswitching specification. Interestingly, the mean growth and variance parameters change only marginally. The influence on the parameters is reflected by a significant reduction in the interest rate effect during periods of below-average growth, the mean estimate decreases (in absolute value) from -1.4 to -0.6 . Moreover, both identified states now display 
Figure 5: Markov switching model with interest rate difference for $p=1$ and $q=1$. Sample period 1978/2-1998/4. Identified model with $\beta_{m 1,1}<\beta_{m 2,1}$. Posterior distribution for $\eta_{i i}, \mu_{i}$ and $\beta_{m i, 1}, i=1,2$, panel (a), (b) and (c), respectively.

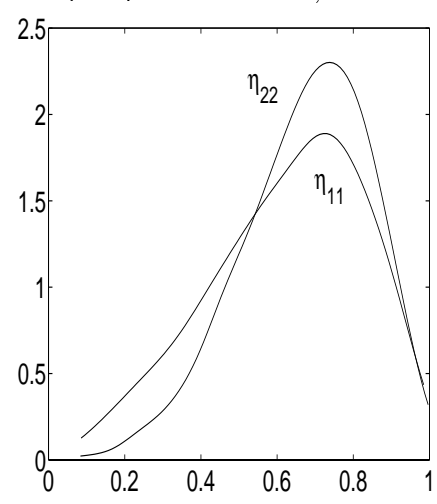

(a)

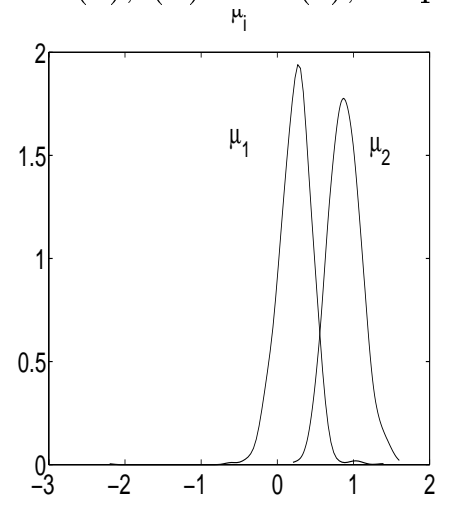

(b)

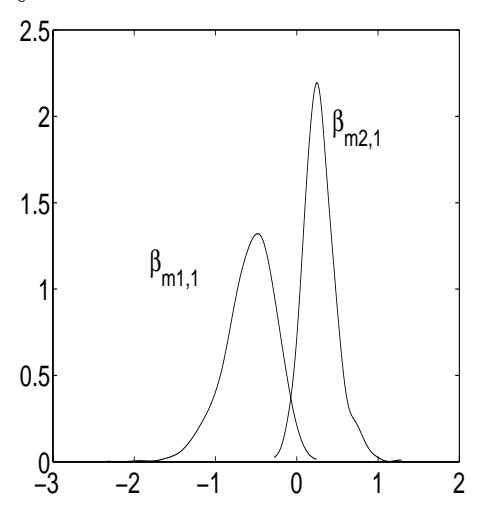

(c)

significant persistence, the mean persistence of remaining in state 1 and state 2 being 0.63 and 0.67 , respectively. Figure 5 displays the posterior distributions of the state-dependent parameters. Overlapping distributions for the persistence parameter reflect the estimation of two states with nearly equal persistence. Moreover, the effect of estimating the model without the outlier on $\beta_{m 2,1}$ is reflected in a rightward shift of its posterior distribution. Finally, note that the mean estimated posterior probability of state 1 (see figure 6) now relates more clearly to periods of economic slack as a whole, and not just to some quarters of it as in the model estimated using the whole sample period. To summarize, even if the presence of an outlier in the observation sample (obviously) influences the inference, it is noteworthy that the basic evidence, namely that monetary policy displays asymmetric effects over time, remains unchanged whether we use the whole or only the restricted sample to obtain it. 
Table 3: Markov switching model with interest rate difference for $p=1$ and $q=1$. Sample period 1978/2-1998/4. Posterior distribution of the model parameters.

\begin{tabular}{|l|rrrrr|}
\hline \hline par & mean & sd & median & \multicolumn{2}{c|}{$95 \%$ conf.int. } \\
\hline$\mu_{1}$ & 0.2403 & 0.2143 & 0.2469 & -0.1967 & 0.6220 \\
$\mu_{2}$ & 0.8809 & 0.2280 & 0.8745 & 0.4532 & 1.3420 \\
$\beta_{y 1}$ & -0.0305 & 0.1221 & -0.0315 & -0.2655 & 0.2089 \\
$\beta_{m 1,1}$ & -0.5690 & 0.3084 & -0.5317 & -1.2836 & -0.0666 \\
$\beta_{m 2,1}$ & 0.2844 & 0.2061 & 0.2691 & -0.0719 & 0.7445 \\
$\sigma$ & 0.4750 & 0.1075 & 0.4623 & 0.3015 & 0.7202 \\
$\eta_{11}$ & 0.6287 & 0.2010 & 0.6567 & 0.1928 & 0.9468 \\
$\eta_{12}$ & 0.3713 & 0.2010 & 0.3432 & 0.0526 & 0.8064 \\
$\eta_{21}$ & 0.3254 & 0.1697 & 0.3068 & 0.0547 & 0.7113 \\
$\eta_{22}$ & 0.6746 & 0.1697 & 0.6932 & 0.2886 & 0.9453 \\
\hline marginal likelihood: $-102.674(0.007)$ \\
marginal likelihood with $\beta_{m 1, i}=\beta_{m 2, i}:-104.315(0.004)$ \\
marginal likelihood with $K=1:-103.734$ \\
\hline \hline
\end{tabular}

Figure 6: Markov switching model with interest rate difference for $p=1$ and $q=1$. Sample period 1978/2-1998/4. Posterior state probabilities with a plot on GDP growth and the interest rate difference.
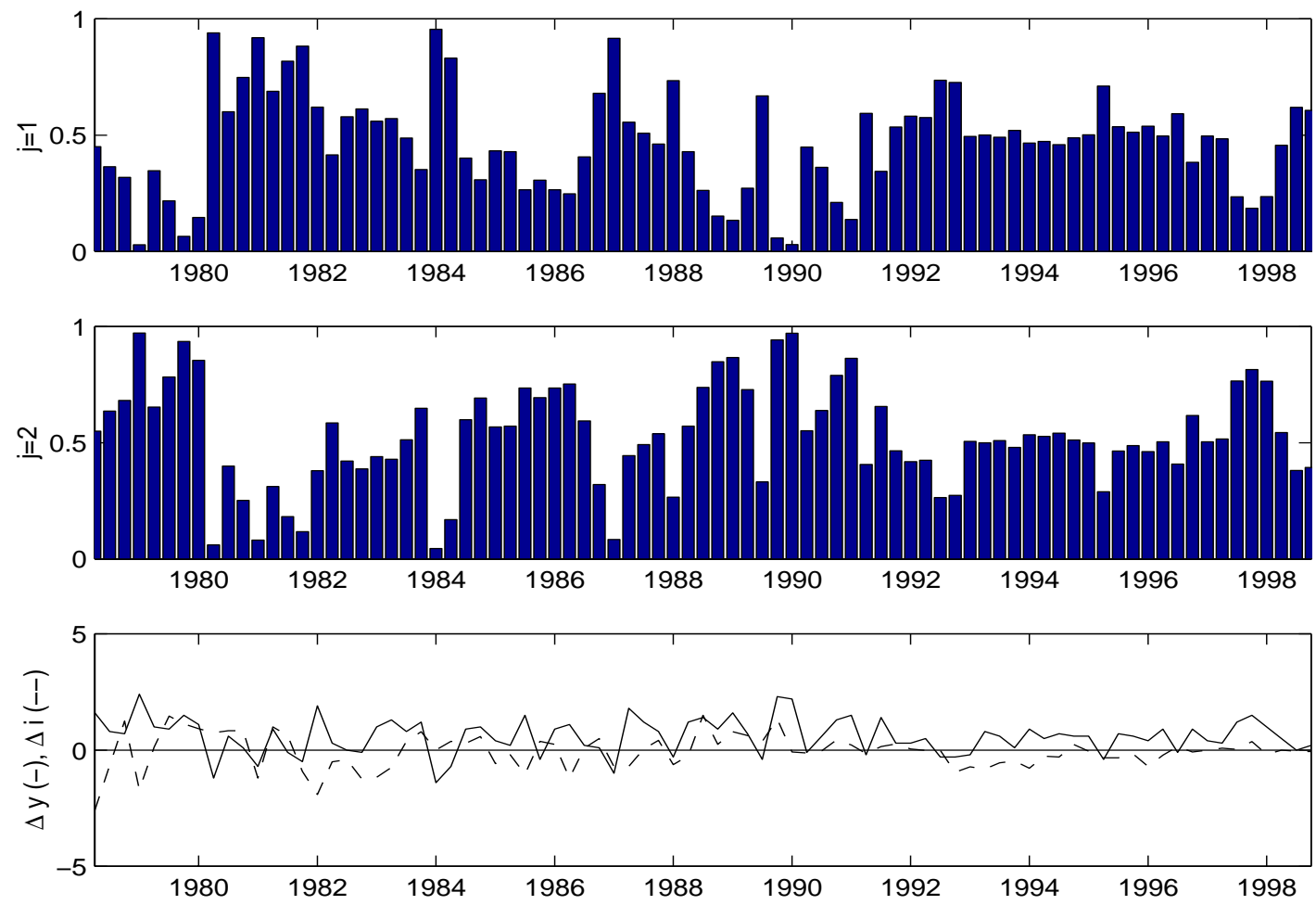


\subsection{Using the interest rate level}

Table 4: Markov switching model with interest rate level for $p=1$ and $q=2$. $\beta_{m i}$, $i=1,2$, refers to the sum over the parameters in state $i, \beta_{m i}=\sum_{j=1}^{2} \beta_{m i, j}$.

\begin{tabular}{|l|rrrrr|}
\hline \hline par & \multicolumn{1}{|c}{ mean } & \multicolumn{1}{c|}{ sd } & median & \multicolumn{2}{c|}{$95 \%$ conf.int. } \\
\hline$\mu_{1}$ & 0.2414 & 0.7104 & 0.2408 & -1.2116 & 1.6574 \\
$\mu_{2}$ & 0.9416 & 0.4458 & 0.9687 & 0.0260 & 1.6811 \\
$\beta_{y 1}$ & -0.0832 & 0.1002 & -0.0816 & -0.2847 & 0.1108 \\
$\beta_{m 1,1}$ & -1.2193 & 0.4322 & -1.2535 & -1.9997 & -0.1441 \\
$\beta_{m 1,2}$ & 1.1696 & 0.5017 & 1.2129 & -0.0312 & 2.0548 \\
$\beta_{m 2,1}$ & 0.0681 & 0.1674 & 0.0550 & -0.2127 & 0.4315 \\
$\beta_{m 2,2}$ & -0.1125 & 0.2219 & -0.0883 & -0.6231 & 0.1752 \\
$\beta_{m 1}$ & -0.0497 & 0.1543 & -0.0280 & -0.4317 & 0.1695 \\
$\beta_{m 2}$ & -0.0444 & 0.1232 & -0.0322 & -0.4575 & 0.0921 \\
$\sigma$ & 0.5531 & 0.1151 & 0.5383 & 0.3696 & 0.8065 \\
$\eta_{11}$ & 0.4476 & 0.2076 & 0.4270 & 0.0956 & 0.9709 \\
$\eta_{12}$ & 0.5524 & 0.2076 & 0.5730 & 0.0290 & 0.9043 \\
$\eta_{21}$ & 0.1854 & 0.1389 & 0.1557 & 0.0151 & 0.5550 \\
$\eta_{22}$ & 0.8146 & 0.1389 & 0.8442 & 0.4443 & 0.9849 \\
\hline marginal likelihood: $-124.761(0.007)$ \\
marginal likelihood with $\beta_{m 1, i}=\beta_{m 2, i}:-127.938$ & $(0.005)$ \\
marginal likelihood with $K=1:-128.279$ & \\
\hline \hline
\end{tabular}

Table 4 presents the results we obtained using the interest rate level as a measure for monetary policy stance rather than the first difference. The model specification that performs best in terms of marginal likelihood is the one with order parameters $p=1$ and $q=2$. The evidence remains broadly unchanged when compared to the results obtained with the interest rate difference. The states relate both to below- and aboveaveraged growth periods, the mean persistence of the former being lower than its switching probability, while the latter displays considerable persistence. A clear significant negative effect of monetary policy is recorded for periods of below-average growth only. The total effect of monetary policy, computed as the sum of the coefficients on the interest rate in each state, $\beta_{m i}=\sum_{j=1}^{2} \beta_{m i, j}, i=1,2$, respectively, seems to be negative on average, the significance of the effect remains doubtful, however. The bottom panel of table 4 documents again that in terms of marginal likelihood a state-dependent specification of the parameters outperforms a specification where the parameters on the interest rate are assumed equal across regimes $\left(\beta_{m 1, i}=\beta_{m 2, i}, i=1,2\right)$ and a specification assuming state-independent parameters $(K=1)$.

Figure 7 depicts the posterior state probabilities obtained by averaging over the sample values of the MCMC output. Despite the relation to business cycle periods becoming weaker in this setting, single quarters within periods of economic slack represent the first 
state. The same comment as before apply to the first quarter in 1978 and to the ones around 1992/93.

Figure 7: Markov switching model with interest rate level for $p=1$ and $q=2$. Posterior state probabilities with a plot on GDP growth and the interest rate.
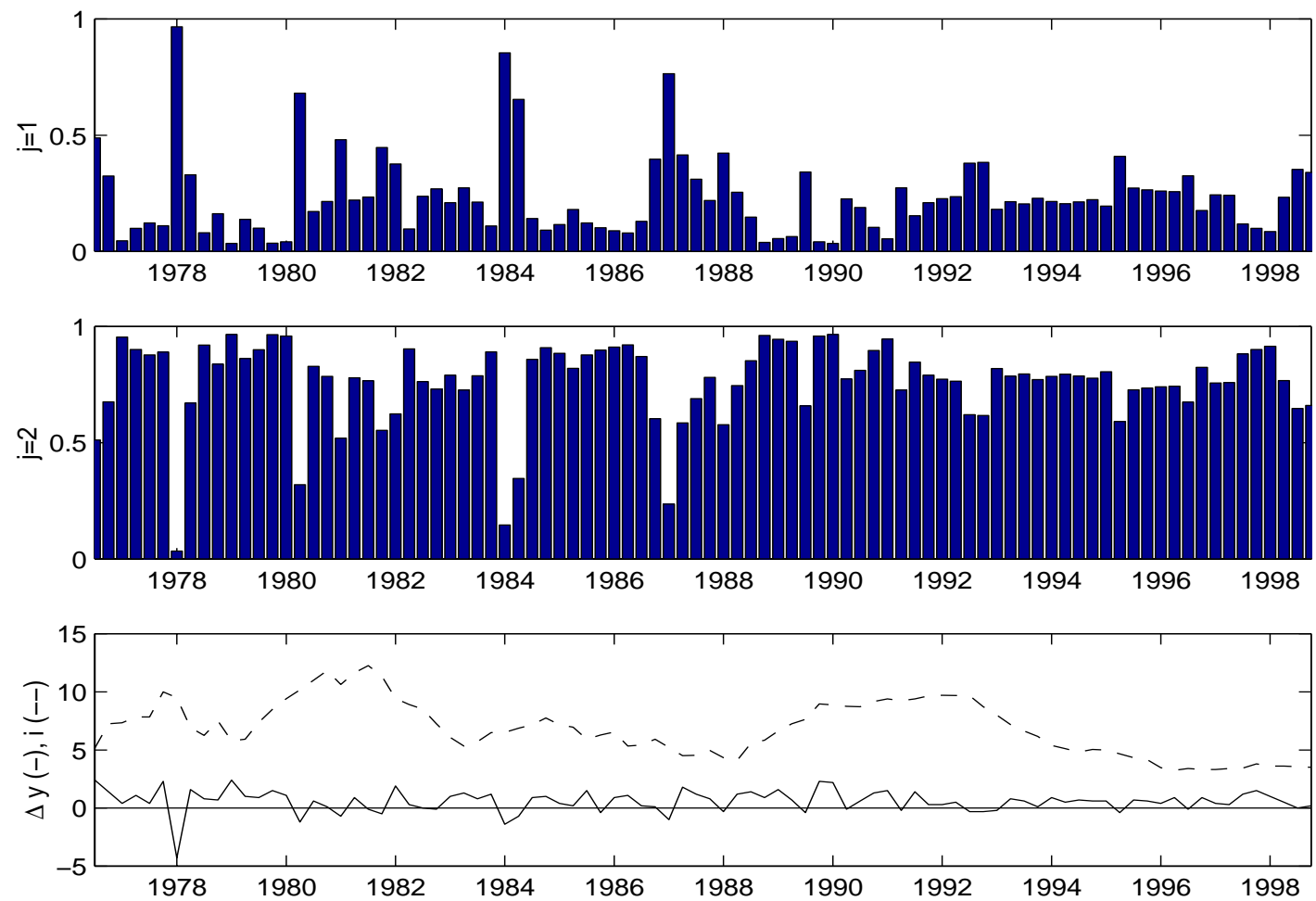

\subsection{Using a policy shock}

So far, the use of the first difference of the interest rate and its level as a measure for monetary policy can be justified by the peg of the Austrian Schilling to the Deutsche Mark (officially since 1981). Austrian rates follow very closely German ones (the correlation being around 0.9) and basically reflect German policy moves. Nevertheless, there may be a residual part in the moves of domestic interest rates necessary to maintain the peg that accommodate domestic shocks. The magnitude of those moves and their effect as well should be small, however, because of the Austrian economy being quite integrated with the German one. The domestic policy shock is estimated with the use of a structural vector autoregression (SVAR) taking into account the relationship of the Austrian with the German economy. ${ }^{3}$ The resulting shock series covers the period 1976/4 to 1998/4. Within this setting the lag order $p$ and $q$ have to be chosen with some caution. It turns

\footnotetext{
${ }^{3}$ The VAR includes real GDP, the unemployment rate, the consumer price index, the 3 -month Austrian interest rate and the nominal effective exchange rate as endogenous variables, and additionally German GDP as exogenous variable. The system is identified by a Cholesky decomposition of the residual co-
} 
out that the specification $p=1, q=6$ performs best in terms of marginal likelihood. However, most of the parameters are insignificant. This result obtains from the artifact of the data already mentioned before. With the high lag specification the effective sample range for the estimation begins in 1978/2 and thus excludes the outlier at the beginning of the sample. Therefore, the best specification is chosen with significant lags is chosen, i.e. $p, q=1$.

Table 5: Markov switching model with domestic policy shock, $p, q=1$. Sample period 1976/4-1998/4.

\begin{tabular}{|l|rrrrr|}
\hline \hline par & mean & sd & median & \multicolumn{2}{c|}{$95 \%$ conf.int. } \\
\hline$\mu_{1}$ & 0.3348 & 0.4088 & 0.3444 & -0.5027 & 1.1731 \\
$\mu_{2}$ & 0.7600 & 0.1666 & 0.7486 & 0.4606 & 1.1088 \\
$\beta_{y 1}$ & -0.1098 & 0.1102 & -0.1061 & -0.3282 & 0.1032 \\
$\beta_{m 1,1}$ & -1.2845 & 0.3481 & -1.2533 & -2.0591 & -0.6776 \\
$\beta_{m 2,1}$ & 0.3017 & 0.3200 & 0.2603 & -0.2073 & 1.1064 \\
$\sigma$ & 0.6073 & 0.1079 & 0.5986 & 0.4252 & 0.8448 \\
$\eta_{11}$ & 0.5370 & 0.2279 & 0.5544 & 0.0981 & 0.9108 \\
$\eta_{12}$ & 0.4630 & 0.2279 & 0.4455 & 0.0891 & 0.9017 \\
$\eta_{21}$ & 0.2068 & 0.1545 & 0.1696 & 0.0147 & 0.6056 \\
$\eta_{22}$ & 0.7932 & 0.1545 & 0.8304 & 0.3939 & 0.9852 \\
\hline marginal likelihood: $-117.210(0.007)$ \\
marginal likelihood with $\beta_{m 1, i}=\beta_{m 2, i}:-123.168(0.009)$ \\
marginal likelihood with $K=1:-122.964$ \\
\hline \hline
\end{tabular}

Table 5 summarizes the posterior distribution of the parameters. Again, the state dependent specification performs best where monetary policy is effective when the low growth regime prevails, while it has no effect on real activity during above-average growth periods. Note also that the persistence of the first state $\left(\eta_{11}\right)$ is low in comparison with the relatively high one of the second state. The posterior state probabilities in figure 8 document that the results are mainly driven by the outlier in the first quarter of 1978, however. Note finally the estimate of the policy shock depicted in the bottom panel of the figure. As expected, it displays only a minor variation.

As a final exercise, the sample is also restricted to exclude the observations previous to $1978 / 2$. As expected above, the effect of domestic policy shocks becomes negligible. Moreover, table 6 reports that the state independent specification now outperforms the switching one (the marginal likelihood even increases when $K=1$ ). This is also reflected by the posterior state probabilities in figure 9 where most of the time the sampler is not able to distinctively identify the prevailing regimes. The mean estimate of policy shock effects remains marginally significantly negative (-0.35 with a standard error of 0.2$).{ }^{4}$

variance matrix. The impulse responses display the expected pattern, and the inclusion of German GDP removes the often encountered price puzzle (see also Valderrama(Valderrama 2001)).

${ }^{4}$ The results of the estimation with $K=1$ are not displayed in detail in order to save space 
Figure 8: Markov switching model with domestic policy shock $p, q=1$. Posterior state probabilities with a plot on GDP growth and the policy shock.
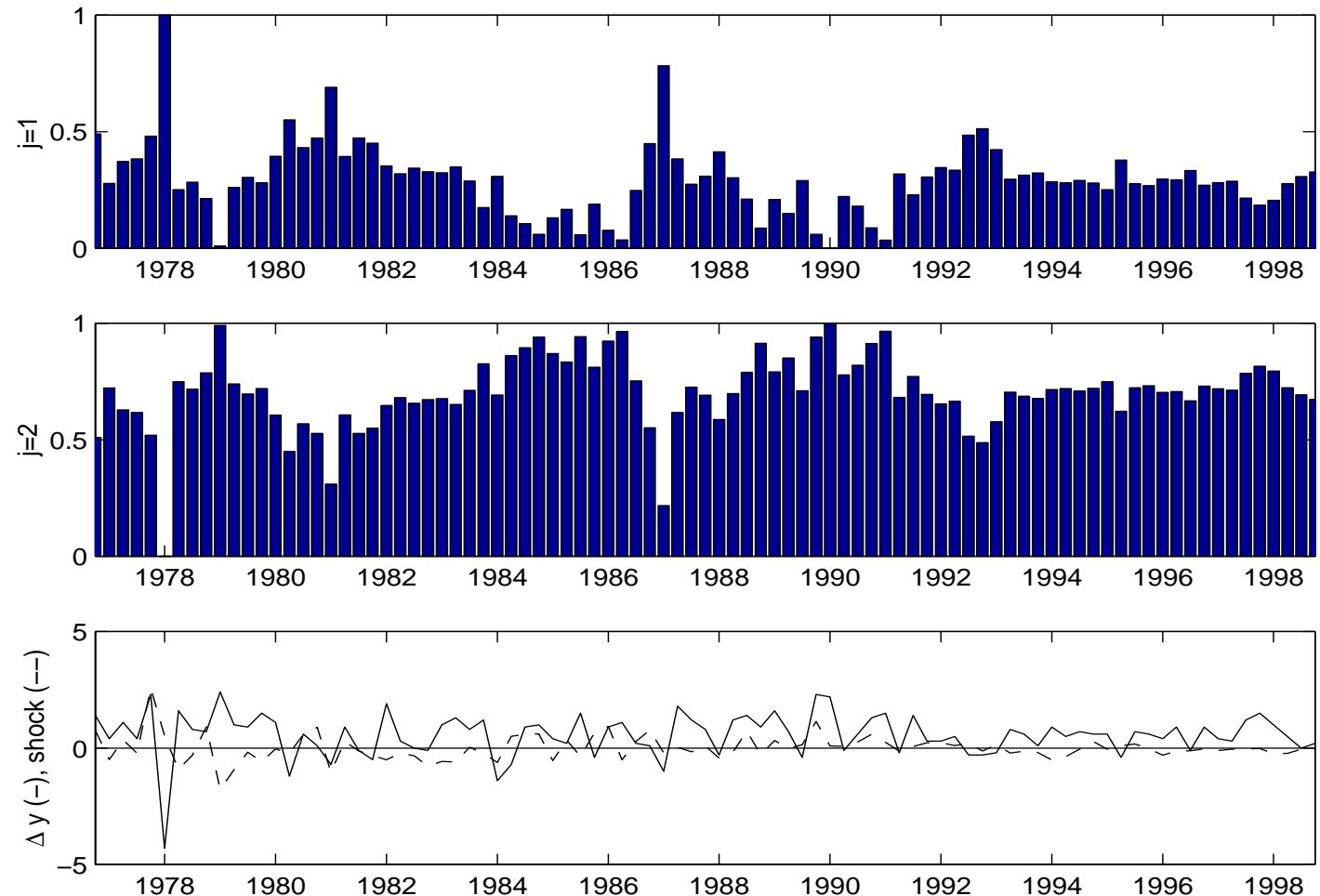

The inference of this section clearly documents that the main policy impulses come from Germany and are propagated through interest rates. While monetary policy in general has significantly negative effects on real activity during periods of low growth, the overall effects of domestic policy shocks are marginally significant, and not asymmetric over time. 
Table 6: Markov switching model with domestic policy shock, $p, q=1$. Sample period $1978 / 2-1998 / 4$.

\begin{tabular}{|l|rrrrr|}
\hline \hline par & mean & sd & median & \multicolumn{2}{c|}{$95 \%$ conf.int. } \\
\hline$\mu_{1}$ & 0.3936 & 0.3517 & 0.4373 & -0.3888 & 0.9394 \\
$\mu_{2}$ & 0.6481 & 0.3772 & 0.6725 & -0.2559 & 1.3234 \\
$\beta_{y 1}$ & -0.0072 & 0.1187 & -0.0061 & -0.2354 & 0.2277 \\
$\beta_{m 1,1}$ & -0.3681 & 0.3832 & -0.3264 & -1.2328 & 0.2421 \\
$\beta_{m 2,1}$ & 0.5392 & 0.4673 & 0.4299 & -0.1279 & 1.7015 \\
$\sigma$ & 0.5716 & 0.1102 & 0.5637 & 0.3787 & 0.8114 \\
$\eta_{11}$ & 0.6838 & 0.2287 & 0.7317 & 0.1547 & 0.9865 \\
$\eta_{12}$ & 0.3162 & 0.2287 & 0.2682 & 0.0135 & 0.8443 \\
$\eta_{21}$ & 0.3425 & 0.2231 & 0.3122 & 0.0131 & 0.8185 \\
$\eta_{22}$ & 0.6575 & 0.2231 & 0.6877 & 0.1814 & 0.9869 \\
\hline marginal likelihood: $-103.475(0.008)$ \\
marginal likelihood with $\beta_{m 1, i}=\beta_{m 2, i}:-103.932(0.008)$ \\
marginal likelihood with $K=1:-103.327$ \\
\hline \hline
\end{tabular}

Figure 9: Markov switching model with domestic policy shock $p, q=1$. Sample period 1978/2-1998/4. Posterior state probabilities with a plot on GDP growth and the policy shock.
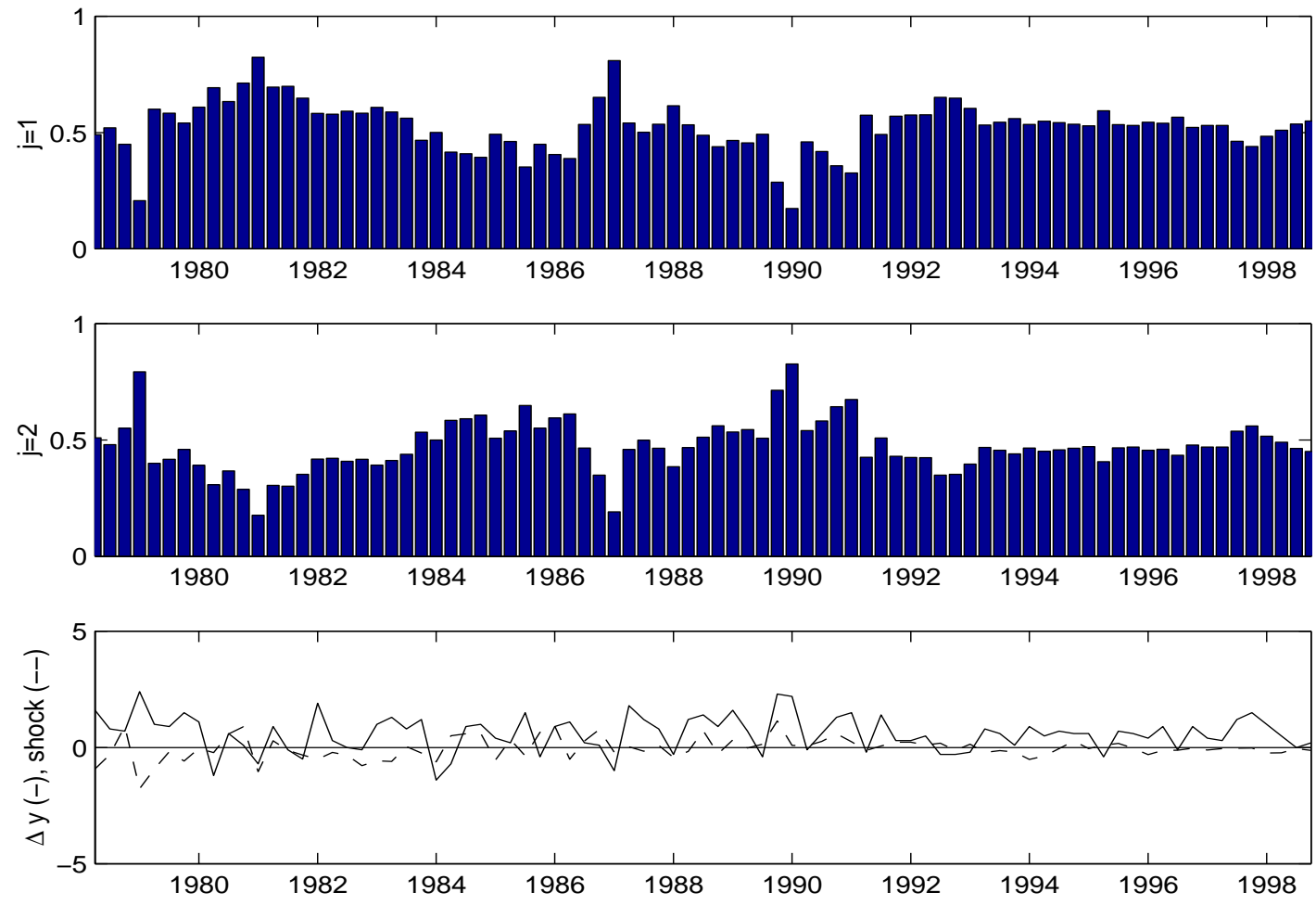


\section{Conclusion}

The present paper assesses whether the effects of monetary policy in Austria are asymmetric over time. We estimate within a Bayesian framework a univariate model for Austrian GDP including additionally the first difference of the 3-month Austrian interest rate as exogenous variable. To measure asymmetric effects of monetary policy the most general specification allows for state dependent coefficients on the interest rate difference, and state dependent constant and variance as well. We apply the random permutation sampler in a first round to perform model selection by means of marginal likelihoods and to find a suitable, unique state-identifying restriction. The results of the identified parsimonious model document a significant negative effect of monetary policy during periods of below-average growth, while the effect appears to be insignificant during periods of normal- or above-average growth. Obviously, quarters of below-average growth occur during periods of economic slack, which is reflected in the plot of posterior state probabilities. The results thus are in line with theoretical derivations of asymmetric effects of monetary policy building on price rigidities and implying a convex supply curve. The basic evidence is refined and remains broadly unchanged when a restricted sample is used for the inference that eliminates the outlier of GDP growth due to the effect that the anticipated introduction of the luxury tax had on sales in the first quarter of 1978.

An additional investigation demonstrates that identifying restrictions have to be set with great care as relatively poor constraints may lead to multimodal posterior distributions that bias the posterior inference. Finally, using the interest rate level rather than the first difference of it does not change the results significantly. A negative effect of monetary policy is again recorded during periods of economic slowdown. The significance of the total effect of monetary policy seems doubtful in both states, however.

To conclude, the results presented here are in line with comparable investigations on European countries. In particular, the Austrian results are in line with those for Germany documented in Kakes (1998), where a significant negative effect of monetary policy is found during recession periods while it is insignificant during boom times. Moreover, when using a monetary policy shock identified by means of a structural vector autoregression, the real effect of monetary policy is insignificant for the Netherlands and Belgium, two small European countries that were also closely following the German Mark. A finding that is reproduced for Austria in the present paper as well when we restrict the sample to exclude the outlier in GDP growth recorded for the first quarter of 1978. Kakes advocates different policy regimes to explain the insignificant response of the Netherlands and Belgium. For Austria however, this might be due to the fact that unexpected interest rate moves necessary to maintain the peg did not have a major effect on the economy due to the high synchronization of the Austrian business cycle with the German one. The results are also compatible with the ones presented in Peersman and Smets (2001) who investigate the asymmetric effects of monetary policy in the Euro area. When using the first difference of the interest rate, they estimate a negative effect of monetary policy during recession times while it is insignificant during boom times. In particular for Austria, they find an overall significant negative effect of monetary policy measured by a shock iden- 
tified on the basis of a Euro area wide SVAR, that is not asymmetric over the business cycle, however. Note finally that, interestingly, the posterior state probabilities of the present analysis are following the ones in Kakes for Germany, and the ones in Peersman and Smets for the European common cycle.

\section{References}

Albert, J. H. and S. Chib (1993). Bayes inference via Gibbs sampling of autoregressive time series subject to Markov mean and variance shifts. Journal of Business \& Economic Statistics 11, 1-15.

Azariadis, C. and B. Smith (1998). Financial intermediation and regime switching in business cycles. The American Economic Review 88, 516-536.

Ball, L. and N. G. Mankiw (1994). Asymmetric price adjustment and economic fluctuations. The Economic Journal 104, 247-261.

Bernanke, B. S. and M. Gertler (1989). Agency costs, net worth, and business fluctuations. The American Economic Review 79, 14-31.

Bernanke, B. S. and M. Gertler (1995). Inside the black box: The credit channel of monetary policy transmission. Working Paper 5146, NBER.

Carter, C. K. and P. Kohn (1994). On Gibbs sampling for state space models. Biometrika 84, 541-553.

Chib, S. (1995). Marginal likelihood from the Gibbs output. Journal of the American Statistical Association 90, 1313-1321.

Chib, S. (1996). Calculating posterior distributions and modal estimates in Markov mixture models. Journal of Econometrics 75, 79-97.

Chib, S. and E. Greenberg (1996). Markov chain Monte Carlo simulation methods in econometrics. Econometric Theory 12, 409-431.

Cover, J. P. (1992). Asymmetric effects of positive and negative money-supply shocks. The Quarterly Journal of Economics 108, 1261-1282.

Farmer, R. E. (1985). Implicit contracts with asymmetric information and bankruptcy: The effect of interest rates on layoffs. Review of Economic Studies 52, 427-442.

Farmer, R. E. (1988). Money and contracts. Review of Economic Studies 55, 431-446.

Frühwirth-Schnatter, S. (1995). Bayesian model discrimination and Bayes factors for linear Gaussian state space models. Journal of the Royal Statistical Society B 5\%, $237-246$.

Frühwirth-Schnatter, S. (1999). Model likelihoods and Bayes factors for switching and mixture models. Technical Report 1999-71, revised version January 2001, Vienna University of Economics and Business Administration.

Frühwirth-Schnatter, S. (2001). MCMC estimation of classical and dynamic switching and mixture models. forthcoming, Journal of the American Statistical Association. 
Garcia, R. and H. Schaller (1995). Are the effects of monetary policy asymmetric? Scientific Series 95s-6, CIRANO.

Hamilton, J. D. (1989). A new approach to the economic analysis of nonstationary time series and the business cycle. Econometrica 57, 357-384.

Hamilton, J. D. (1990). Analysis of time series subject to changes in regime. Journal of Econometrics 45, 39-70.

Kakes, J. (1998). Monetary transmission and business cycle asymmetry. SOM research report 98C36, University of Groningen.

Karras, G. (1996a). Are the output effects of monetary policy asymmetric? Evidence from a sample of European countries. Oxford Bulletin of Economics and Statistics 58, 267-278.

Karras, G. (1996b). Why are the effects of money-supply shocks asymmetric? Convex aggregate supply or "pushing on a string"? Journal of Macroeconomics 18, 605-619.

Kaufmann, S. (2000). Measuring business cycles with a dynamic Markov switching factor model: an assessment using Bayesian simulation methods. The Econometrics Journal 3, 39-65.

Kaufmann, S. and S. Frühwirth-Schnatter (2000). Bayesian analysis of switching ARCH models. Journal of Time Series Analysis, forthcoming.

Kim, C.-J. and C. R. Nelson (1998). Business cycle turning points, a new coincident index, and tests of duration dependence based on a dynamic factor model with regime-switching. Review of Economics \& Statistics 80, 188-201.

Kim, C.-J. and C. R. Nelson (1999). State-Space Models with Regime Switching. Cambridge, Massachusetts: MIT Press.

Kiyotaki, N. (1998). Credit and business cycles. The Japanese Economic Review 49, 18-35.

Kiyotaki, N. and J. Moore (1997a, January). Credit chains. mimeo.

Kiyotaki, N. and J. Moore (1997b). Credit cycles. Journal of Political Economy 105, 211-248.

Lenz, C. (1997). Asymmetric effects of monetary policy in Switzerland. Swiss Journal of Economics and Statistics 133, 441-454.

Meng, X. and W. Wong (1996). Simulating ratios of normalising constants via a simple identity. Statistica Sinica 6, 831-860.

Peersman, G. and F. Smets (2001). Are the effects of monetary policy in the Euro area greater in recessions than in booms? Working Paper 52, European Central Bank.

Shephard, N. (1994). Partial non-Gaussian state space. Biometrika 81, 115-131.

Smith, A. and G. Roberts (1993). Bayesian computation via the Gibbs sampler and related Markov Chain Monte Carlo methods. Journal of the Royal Statistical Society B 55, 3-23. 
Tsiddon, D. (1993). The (mis)behaviour of the aggregate price level. Review of Economic Studies 60, 889-902.

Valderrama, M. (2001, May). Monetary shocks and investment behaviour in Austria: A microeconometric approach. mimeo, Oesterreichische Nationalbank. 


\section{Index of Working Papers:}

$\left.\begin{array}{l}\text { August 28, Pauer Franz } \\ 1990\end{array} \quad 1^{1}\right) \quad \begin{aligned} & \text { Hat Böhm-Bawerk Recht gehabt? Zum Zu- } \\ & \text { sammenhang zwischen Handelsbilanzpas- } \\ & \text { sivum und Budgetdefizit in den USA }{ }^{2)}\end{aligned}$

\begin{tabular}{|c|c|c|c|}
\hline $\begin{array}{l}\text { March 20, } \\
1991\end{array}$ & Backé Peter & $2^{1)}$ & $\begin{array}{l}\text { Ost- und Mitteleuropa auf dem Weg zur } \\
\text { Marktwirtschaft - Anpassungskrise } 1990\end{array}$ \\
\hline
\end{tabular}

$\begin{array}{lll}\begin{array}{l}\text { March 14, Pauer Franz } \\ 1991\end{array} & 3^{1)} & \begin{array}{l}\text { Die Wirtschaft Österreichs im Vergleich zu } \\ \text { den EG-Staaten - eine makroökonomische } \\ \text { Analyse für die 80er Jahre }\end{array}\end{array}$

May 28, 1991 Mauler Kurt $\quad 4^{1)} \quad$ The Soviet Banking Reform

\begin{tabular}{|c|c|c|c|}
\hline July 16, 1991 & Pauer Franz & $5^{1)}$ & $\begin{array}{l}\text { Die Auswirkungen der Finanzmarkt- und } \\
\text { Kapitalverkehrsliberalisierung auf die } \\
\text { Wirtschaftsentwicklung und Wirtschafts- } \\
\text { politik in Norwegen, Schweden, Finnland } \\
\text { und Großbritannien - mögliche Konse- } \\
\text { quenzen für Österreich) }\end{array}$ \\
\hline
\end{tabular}

\begin{tabular}{llcl}
\hline August 1, 1991 Backé Peter & $6^{1)}$ & $\begin{array}{l}\text { Zwei Jahre G-24-Prozess: Bestandsauf- } \\
\text { nahme und Perspektiven unter besonderer } \\
\text { Berücksichtigung makroökonomischer } \\
\text { Unterstützungsleistungen }\end{array}$ \\
\hline August 8, 1991 Holzmann Robert & $7^{1)}$ & $\begin{array}{l}\text { Die Finanzoperationen der öffentlichen } \\
\text { Haushalte der Reformländer CSFR, Polen } \\
\text { und Ungarn: Eine erste quantitative Analyse }\end{array}$ \\
\hline $\begin{array}{lll}\text { January 27, } \\
1992\end{array}$ & Pauer Franz & $8^{1)}$ & $\begin{array}{l}\text { Erfüllung der Konvergenzkriterien durch die } \\
\text { EG-Staaten und die EG-Mitgliedswerber } \\
\text { Schweden und Österreich }\end{array}$ \\
& & &
\end{tabular}

1) vergriffen (out of print)

2) In abgeänderter Form erschienen in Berichte und Studien Nr. 4/1990, S 74 ff

3) In abgeänderter Form erschienen in Berichte und Studien Nr. 4/1991, S 44 ff

4) In abgeänderter Form erschienen in Berichte und Studien Nr. 3/1991, S 39 ff

5) In abgeänderter Form erschienen in Berichte und Studien Nr. 1/1992, S 54 ff 


\begin{tabular}{|c|c|c|c|}
\hline $\begin{array}{l}\text { October } 12 \\
1992\end{array}$ & $\begin{array}{l}\text { Hochreiter Eduard } \\
\text { (Editor) }\end{array}$ & $9^{1)}$ & $\begin{array}{l}\text { Alternative Strategies For Overcoming the } \\
\text { Current Output Decline of Economies in } \\
\text { Transition }\end{array}$ \\
\hline $\begin{array}{l}\text { November 10, } \\
1992\end{array}$ & $\begin{array}{l}\text { Hochreiter Eduard } \\
\text { and Winckler Georg }\end{array}$ & $10^{1)}$ & $\begin{array}{l}\text { Signaling a Hard Currency Strategy: The } \\
\text { Case of Austria }\end{array}$ \\
\hline March 12, 1993 & $\begin{array}{l}\text { Hochreiter Eduard } \\
\text { (Editor) }\end{array}$ & 11 & $\begin{array}{l}\text { The Impact of the Opening-up of the East on } \\
\text { the Austrian Economy - A First Quantitative } \\
\text { Assessment }\end{array}$ \\
\hline June 8, 1993 & Anulova Guzel & 12 & The Scope for Regional Autonomy in Russia \\
\hline July 14,1993 & Mundell Robert & 13 & $\begin{array}{l}\text { EMU and the International Monetary System } \\
\text { A Transatlantic Perspective }\end{array}$ \\
\hline $\begin{array}{l}\text { November 29, } \\
1993\end{array}$ & Hochreiter Eduard & 14 & $\begin{array}{l}\text { Austria's Role as a Bridgehead Between } \\
\text { East and West }\end{array}$ \\
\hline March 8, 1994 & $\begin{array}{l}\text { Hochreiter Eduard } \\
\text { (Editor) }\end{array}$ & 15 & Prospects for Growth in Eastern Europe \\
\hline June 8, 1994 & Mader Richard & 16 & A Survey of the Austrian Capital Market \\
\hline $\begin{array}{l}\text { September } 1 \\
1994\end{array}$ & $\begin{array}{l}\text { Andersen Palle and } \\
\text { Dittus Peter }\end{array}$ & 17 & $\begin{array}{l}\text { Trade and Employment: Can We Afford } \\
\text { Better Market Access for Eastern Europe? }\end{array}$ \\
\hline $\begin{array}{l}\text { November } 21 \\
1994\end{array}$ & Rautava Jouko & $18^{1)}$ & $\begin{array}{l}\text { Interdependence of Politics and Economic } \\
\text { Development: Financial Stabilization in } \\
\text { Russia }\end{array}$ \\
\hline $\begin{array}{l}\text { January 30, } \\
1995\end{array}$ & $\begin{array}{l}\text { Hochreiter Eduard } \\
\text { (Editor) }\end{array}$ & 19 & $\begin{array}{l}\text { Austrian Exchange Rate Policy and } \\
\text { European Monetary Integration - Selected } \\
\text { Issues }\end{array}$ \\
\hline $\begin{array}{l}\text { October 3, } \\
1995\end{array}$ & Groeneveld Hans & 20 & $\begin{array}{l}\text { Monetary Spill-over Effects in the ERM: The } \\
\text { Case of Austria, a Former Shadow Member }\end{array}$ \\
\hline
\end{tabular}




\begin{tabular}{|c|c|c|c|}
\hline $\begin{array}{l}\text { December 6, } \\
1995\end{array}$ & Frydman Roman et al & 21 & $\begin{array}{l}\text { Investing in Insider-dominated Firms: A } \\
\text { Study of Voucher Privatization Funds in } \\
\text { Russia }\end{array}$ \\
\hline March 5, 1996 & Wissels Rutger & 22 & $\begin{array}{l}\text { Recovery in Eastern Europe: Pessimism } \\
\text { Confounded? }\end{array}$ \\
\hline June 25, 1996 & Pauer Franz & 23 & $\begin{array}{l}\text { Will Asymmetric Shocks Pose a Serious } \\
\text { Problem in EMU? }\end{array}$ \\
\hline $\begin{array}{l}\text { September } 19 \\
1997\end{array}$ & Koch Elmar B. & 24 & $\begin{array}{l}\text { Exchange Rates and Monetary Policy in } \\
\text { Central Europe - a Survey of Some Issues }\end{array}$ \\
\hline April 15, 1998 & Weber Axel A. & 25 & $\begin{array}{l}\text { Sources of Currency Crises: An Empirical } \\
\text { Analysis }\end{array}$ \\
\hline May 28,1998 & $\begin{array}{l}\text { Brandner Peter, } \\
\text { Diebalek Leopold } \\
\text { and Schuberth } \\
\text { Helene }\end{array}$ & 26 & $\begin{array}{l}\text { Structural Budget Deficits and Sustainability } \\
\text { of Fiscal Positions in the European Union }\end{array}$ \\
\hline June 15, 1998 & $\begin{array}{l}\text { Canzeroni Matthew, } \\
\text { Cumby Robert, Diba } \\
\text { Behzad and Eudey } \\
\text { Gwen }\end{array}$ & 27 & $\begin{array}{l}\text { Trends in European Productivity: } \\
\text { Implications for Real Exchange Rates, Real } \\
\text { Interest Rates and Inflation Differentials }\end{array}$ \\
\hline June 20, 1998 & MacDonald Ronald & 28 & $\begin{array}{l}\text { What Do We Really Know About Real } \\
\text { Exchange Rates? }\end{array}$ \\
\hline June 30, 1998 & $\begin{array}{l}\text { Campa José and } \\
\text { Wolf Holger }\end{array}$ & 29 & $\begin{array}{l}\text { Goods Arbitrage and Real Exchange Rate } \\
\text { Stationarity }\end{array}$ \\
\hline July 3,1998 & Papell David H. & 30 & $\begin{array}{l}\text { The Great Appreciation, the Great } \\
\text { Depreciation, and the Purchasing Power } \\
\text { Parity Hypothesis }\end{array}$ \\
\hline July 20,1998 & Chinn Menzie David & 31 & $\begin{array}{l}\text { The Usual Suspects? Productivity and } \\
\text { Demand Shocks and Asia-Pacific Real } \\
\text { Exchange Rates }\end{array}$ \\
\hline
\end{tabular}




\begin{tabular}{|c|c|c|c|}
\hline July 30,1998 & $\begin{array}{l}\text { Cecchetti Stephen } \\
\text { G., Mark Nelson C., } \\
\text { Sonora Robert }\end{array}$ & 32 & $\begin{array}{l}\text { Price Level Convergence Among United } \\
\text { States Cities: Lessons for the European } \\
\text { Central Bank }\end{array}$ \\
\hline $\begin{array}{l}\text { September } \\
30,1998\end{array}$ & $\begin{array}{l}\text { Christine Gartner, } \\
\text { Gert Wehinger }\end{array}$ & 33 & $\begin{array}{l}\text { Core Inflation in Selected European Union } \\
\text { Countries }\end{array}$ \\
\hline $\begin{array}{l}\text { November } \\
5,1998\end{array}$ & $\begin{array}{l}\text { José Viñals and } \\
\text { Juan F. Jimeno }\end{array}$ & 34 & $\begin{array}{l}\text { The Impact of EMU on European } \\
\text { Unemployment }\end{array}$ \\
\hline $\begin{array}{l}\text { December } \\
11,1998\end{array}$ & $\begin{array}{l}\text { Helene Schuberth } \\
\text { and Gert Wehinger }\end{array}$ & 35 & $\begin{array}{l}\text { Room for Manoeuvre of Economic Policy in } \\
\text { the EU Countries - Are there Costs of } \\
\text { Joining EMU? }\end{array}$ \\
\hline $\begin{array}{l}\text { December } \\
21,1998\end{array}$ & $\begin{array}{l}\text { Dennis C. Mueller } \\
\text { and Burkhard Raunig }\end{array}$ & 36 & $\begin{array}{l}\text { Heterogeneities within Industries and } \\
\text { Structure-Performance Models }\end{array}$ \\
\hline $\begin{array}{l}\text { May } \\
21,1999\end{array}$ & $\begin{array}{l}\text { Alois Geyer and } \\
\text { Richard Mader }\end{array}$ & 37 & $\begin{array}{l}\text { Estimation of the Term Structure of Interest } \\
\text { Rates - A Parametric Approach }\end{array}$ \\
\hline $\begin{array}{l}\text { July } \\
29,1999\end{array}$ & $\begin{array}{l}\text { José Viñals and } \\
\text { Javier Vallés }\end{array}$ & 38 & $\begin{array}{l}\text { On the Real Effects of Monetary Policy: A } \\
\text { Central Banker's View }\end{array}$ \\
\hline $\begin{array}{l}\text { December } \\
20,1999\end{array}$ & $\begin{array}{l}\text { John R. Freeman, } \\
\text { Jude C. Hays and } \\
\text { Helmut Stix }\end{array}$ & 39 & $\begin{array}{l}\text { Democracy and Markets: The Case of } \\
\text { Exchange Rates }\end{array}$ \\
\hline $\begin{array}{l}\text { March } \\
1,2000\end{array}$ & $\begin{array}{l}\text { Eduard Hochreiter } \\
\text { and Tadeusz } \\
\text { Kowalski }\end{array}$ & 40 & $\begin{array}{l}\text { Central Banks in European Emerging Market } \\
\text { Economies in the 1990s }\end{array}$ \\
\hline $\begin{array}{l}\text { March } \\
20,2000\end{array}$ & Katrin Wesche & 41 & $\begin{array}{l}\text { Is there a Credit Channel in Austria? } \\
\text { The Impact of Monetary Policy on Firms' } \\
\text { Investment Decisions }\end{array}$ \\
\hline $\begin{array}{l}\text { June } \\
20,2000\end{array}$ & $\begin{array}{l}\text { Jarko Fidrmuc and } \\
\text { Jan Fidrmuc }\end{array}$ & 42 & $\begin{array}{l}\text { Integration, Disintegration and Trade in } \\
\text { Europe: Evolution of Trade Relations During } \\
\text { the 1990s }\end{array}$ \\
\hline
\end{tabular}




\begin{tabular}{|c|c|c|c|}
\hline $\begin{array}{l}\text { March } \\
06,2001\end{array}$ & Marc Flandreau & 43 & $\begin{array}{l}\text { The Bank, the States, and the Market, } \\
\text { A Austro-Hungarian Tale for Euroland, } \\
\text { 1867-1914 }\end{array}$ \\
\hline $\begin{array}{l}\text { May } \\
01,2001\end{array}$ & Otmar Issing & 44 & $\begin{array}{l}\text { The Euro Area and the Single Monetary } \\
\text { Policy }\end{array}$ \\
\hline $\begin{array}{l}\text { May } \\
18,2001\end{array}$ & Sylvia Kaufmann & 45 & $\begin{array}{l}\text { Is there an asymmetric effect of monetary } \\
\text { policy over time? A Bayesian analysis using } \\
\text { Austrian data }\end{array}$ \\
\hline
\end{tabular}

